\title{
Medical Management of Placenta Accreta with Methotrexate: Review of Two Cases
}

\author{
${ }^{1}$ Yoginder Singh, ${ }^{2}$ Vinod Raghav, ${ }^{3}$ A Kapur
}

\begin{abstract}
Placenta accreta is a potentially life-threatening obstetric condition that requires a multidisciplinary approach for its management. The incidence of placenta accreta has increased over the years. Women at greatest risk of placenta accreta are those who have myometrial damage caused by a previous cesarean delivery. Although recognized obstetric risk factors allow the identification of most cases during the antepartum period, the diagnosis is occasionally discovered at the time of delivery when there is difficulty in delivery of placenta. In general, the recommended management of suspected placenta accreta is planned preterm cesarean hysterectomy with the placenta left in situ because attempts at removal of the placenta are associated with significant hemorrhagic morbidity. Recently, adjuvant therapy with methotrexate has been used in the treatment of morbidly adherent placenta in patients desiring further child bearing. We present two cases where medical management was successful.
\end{abstract}

Keywords: Placenta accreta, Medical management, Methotrexate.

How to cite this article: Singh Y, Raghav V, Kapur A. Medical Management of Placenta Accreta with Methotrexate: Review of Two Cases. J South Asian Feder Obst Gynae 2015;7(2):86-88.

Source of support: Nil

Conflict of interest: None

Date of received: 10 May 2015

Date of acceptance: 18 June 2015

Date of publication: August 2015

\section{INTRODUCTION}

The placenta accreta is an abnormality in placentation when the anchoring placental villi are directly in

\footnotetext{
${ }^{1}$ Professor and Head, ${ }^{2}$ Professor (Deputy Commandant) ${ }^{3}$ Professor

${ }^{1}$ Department of Obstetrics and Gynecology, Fetal Medicine Command Hospital, Lucknow, Uttar Pradesh, India

${ }^{2}$ Department of Pathology, Command Hospital, Lucknow, Uttar Pradesh, India

${ }^{3}$ Department of Obstetrics and Gynecology, Armed Forces Medical College, Pune, Maharashtra, India

Corresponding Author: Yoginder Singh, Professor and Head Department of Obstetrics and Gynecology, Fetal Medicine Command Hospital, Lucknow-226002, Uttar Pradesh, India e-mail: yogirana1@gmail.com
}

contact with myometrium resulting in firm attachment of placenta to the uterine wall leading to its incomplete separation at the time of delivery. It is usually diagnosed after delivery when manual removal of the retained placenta fails. ${ }^{1,2}$ The complications may include severe postpartum hemorrhage, uterine perforation, shock, infection, loss of fertility and even death. Over the last few decades, the incidence of placenta accreta has increased. The conventional treatment is hysterectomy. Recently, adjuvant therapy with methotrexate has been used in the treatment of morbidly adherent placenta. We present two such cases with successful outcome.

\section{CASE REPORTS}

\section{Case 1}

A 25 years old primi was referred to our tertiary care hospital on 26 July, 2009 with history of full term vaginal delivery and retained placenta for more 10 hours. On admission, there was no pallor, vitals were normal and there was no bleeding per vaginum. On abdominal, examination, uterus was 18 to 20 weeks gravid size and well contracted. She was put on broad spectrum antibiotics. Patient was taken to operation theater for manual removal of placenta which failed. Since there was no active bleeding per vaginum and patient was desirous of retaining her fertility conservative management was planned. Doppler imaging of uterus showed diffuse intraparenchymal placental lacunar flow, focal intraparenchymal placental lacunar flow, thinning of myometrium overlying the placenta, loss of retroplacental 'sonolucent line'. Magnetic resonance imaging (MRI) confirmed the diagnosis of placenta percreta. We administered methotrexate intramuscularly in the doses of $1 \mathrm{mg}$ per meter square weekly (total 4 doses) and was monitored with $\beta$-hCG, leucocyte counts and LFT. Patient was followed weekly with ultrasound Doppler which showed gradual decrease in vascularity of placenta (Figs 1 and 2). Six months after, methotrexate treatment retained placenta had totally resolved and patient conceived spontaneously 14 months after treatment.

\section{Case 2}

A 23 years old primi a booked antenatal case at our unit had spontaneous vaginal delivery on 23 August 2011. She 


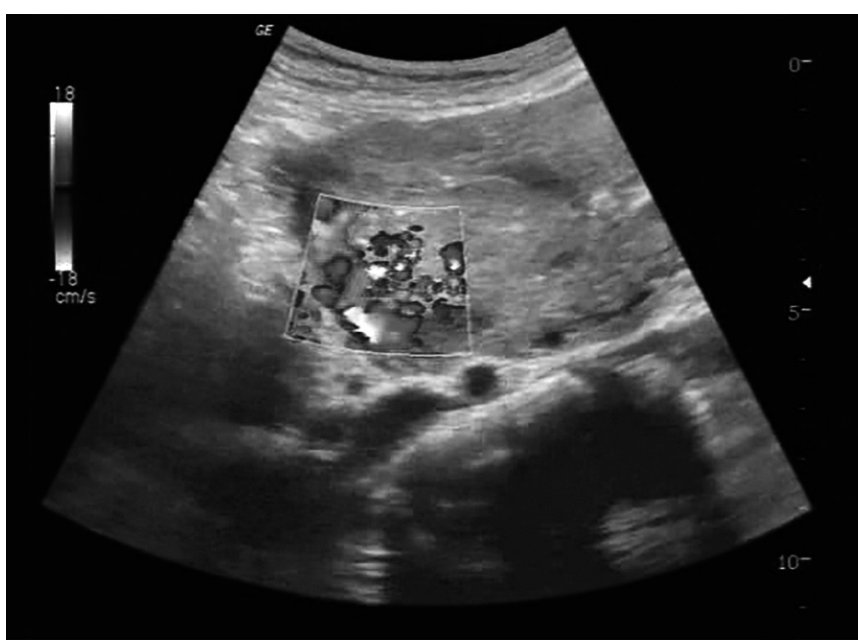

Fig. 1: Ultrasonography (USG) color Doppler showing retained placenta with loss of retroplacental sonolucent line and marked vascularity

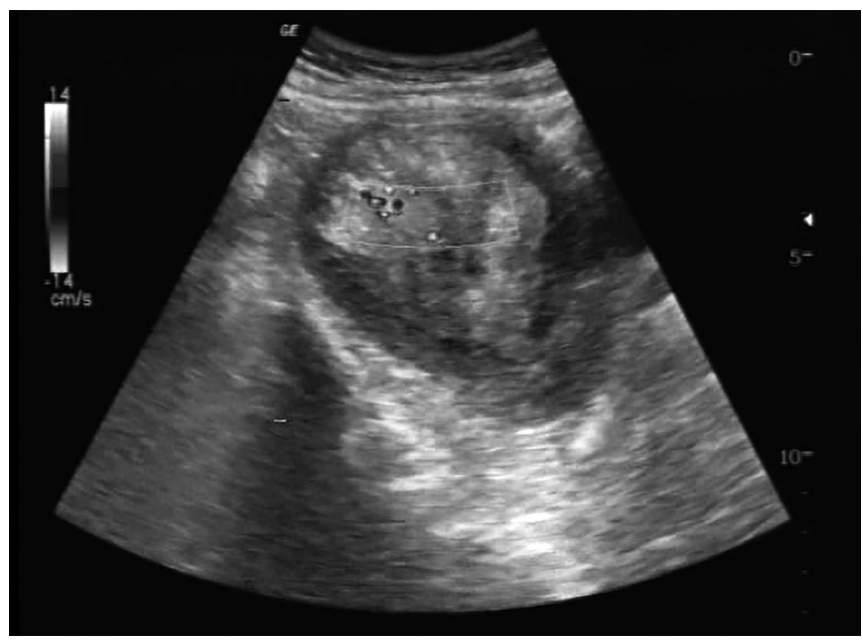

Fig. 3: Ultrasound picture of retained placenta of case 2

had no significant history and her antenatal period was uneventful. After delivery of the newborn, placenta was retained for more than 1 hour. There was no bleeding per vaginum and uterus was well contracted, urgent ultrasound Doppler showed evidence of placenta accreta (Fig. 3) which was further confirmed by MRI which was done next day. In view patient's desire for future childbearing, she was planned for medical management as in patient with methotrexate. She was given methotrexate intramuscularly in the doses of $1 \mathrm{mg} / \mathrm{m}^{2}$ weekly (total 3 doses).

Patient was followed weekly with ultrasound Doppler and serum $\beta$-hCG. There was one episode of bleeding per vaginum 2 days after second dose with passage of flashy mass; however, patient was stable and did not require any blood transfusion. Two months after, methotrexate treatment patient had near normal ultrasound findings and $\beta$-hCG value of less than $5 \mathrm{mIU} / \mathrm{ml}$.

\section{DISCUSSION}

Placenta accreta is used to describe any implantation in which there is abnormally firm adherence to the uterine

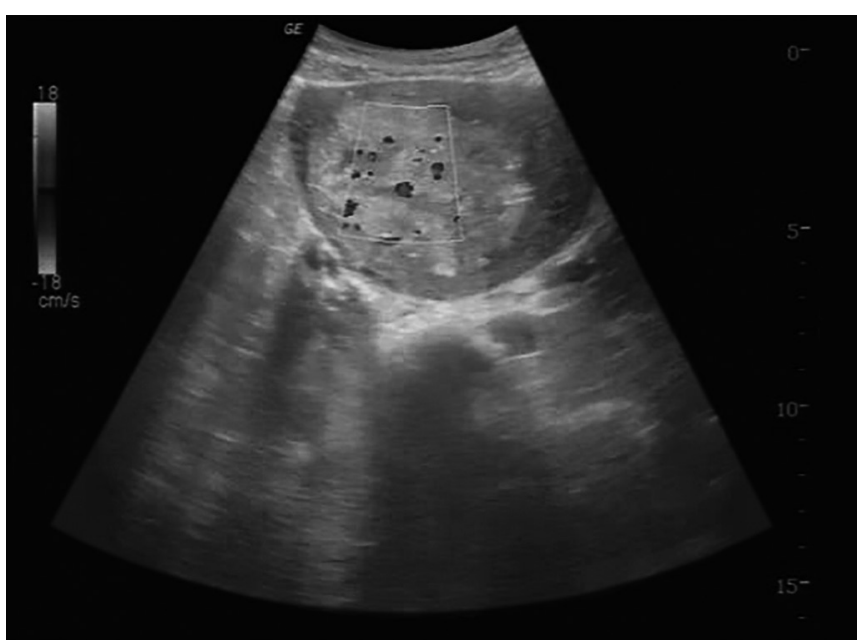

Fig. 2: Gradual decrease in vascularity after methotrexate therapy

wall. As a consequence of partial or total absence of decidua basalis and imperfect development of the fibrinoid or the Nitabuch layer, placental villi are directly attached to the myometrium in placenta accreta. ${ }^{3}$ The incidence of placenta accreta has been increasing largely due to the global increase in caesarean deliveries. The American College of Obstetrician and Gynecologist in 2002 , estimated that placenta accreta complicates 1 in 2500 pregnancies, whereas incidence reported in 2006 is 1 in 2103. It is a life threatening condition associated with high maternal morbidity and mortality rate being as high as $7 \%$. Optimal management of abnormally invasive placentation is still not clear. Traditionally, primary hysterectomy at the time of caesarean has been the mainstay of therapy particularly in cases where diagnosis has been made antenataly. ${ }^{4}$ Presently, there has been gradual shift toward conservative management of this condition. These may include uterine conservation and leaving the morbidly adherent placenta in situ with either adjuvant treatment with methotrexate or simply awaiting its spontaneous resorption. Tong et al pioneered the conservative management of morbidly adherent placenta by systemic administration of methotrexate. ${ }^{5}$ The outcome varies widely ranging from expulsion at 7 days to progressive resorption in roughly 6 months. As of now there are no accepted protocol regarding dose and duration of methotrexate as only limited experience is available in literature. ${ }^{6}$ Although, conservative management with methotrexate appears to be safe there are potential risks of infection and bleeding and, hence, patient should be under close observation. The prognostic implications of decreasing serum $\beta$-hCG levels following administration methotrexate are better described in the setting of ectopic pregnancy. For placenta accreta, it is not clear whether decreasing levels correlate with the rate of involution of placental tissue. Our two cases demonstrate 
that conservative management of morbidly adherent retained placenta with methotrexate can be successful. In our cases, systemic administration of methotrexate resulted in reduction of placental size, decreased uteroplacental vascularity (Figs 1 and 2) eventually resulting in decrease and disappearance of the placental tissue. In our first case, patient conceived after methotrexate while second patient is still under follow-up. So, in selected cases, conservative management with methotrexate may be tried. Early diagnosis is important because patient can be adequately counseled with regard to treatment options and their possible consequences. Aim of this short communication is to give massage to practising obstetrician that conservative medical management of morbidly adherent retained placenta may be considered in selected cases.

\section{REFERENCES}

1. Nijman RGW, Mantigh A, Aanoudse JG. Persistent retained placenta percreta: methotrexate treatment and Doppler flow characteristics. BJOG 2002;109(5):587-588.

2. Chou MM, Ho ES, Lee YH. Prenatal diagnosis of placenta accreta by trans abdominal colour Doppler ultrasound. Ultrasound Obstet Gynecol 2000;15(1):28-35.

3. Khong TY. The pathology of placenta accreta: a worldwide epidemic. J Clin Pathol 2008;61(2):1243-1246.

4. Wu S, Kocherginsky M, Hibbard JU. Abnormal placentation: 20-year analysis. Am J Obstet Gynecol 2005;192(5): 1458-1461.

5. Tong SYP, Tay KH, Kwek YCK. Conservative management of placenta accreta: review of three cases. Singapore Med J 2008;49(6):156-159.

6. Robinson BK, Grobman WA. Effectiveness of timing strategies for delivery of individuals with placenta previa and accreta. Obstet Gynecol 2010 Sep;116:835-842. 